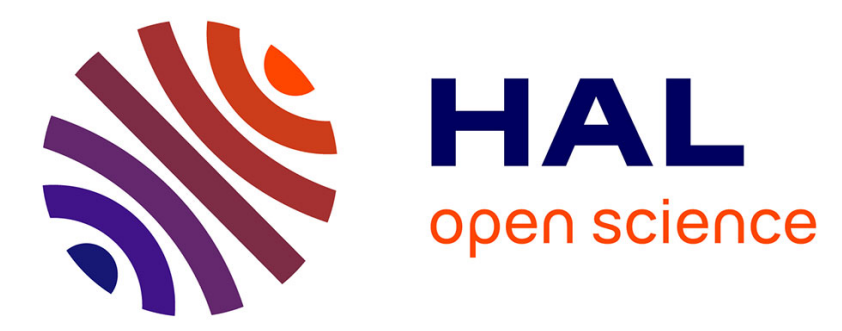

\title{
Mass determination of molecules of biological interest by fast heavy ions induced desorption mass spectrometry
}

\author{
Y. Le Beyec, S. Della Negra, C. Deprun, P. Vigny, Y.M. Ginot
}

\section{To cite this version:}

Y. Le Beyec, S. Della Negra, C. Deprun, P. Vigny, Y.M. Ginot. Mass determination of molecules of biological interest by fast heavy ions induced desorption mass spectrometry. Revue de Physique Appliquée, 1980, 15 (12), pp.1631-1637. 10.1051/rphysap:0198000150120163100 . jpa-00244891

\section{HAL Id: jpa-00244891 https://hal.science/jpa-00244891}

Submitted on 1 Jan 1980

HAL is a multi-disciplinary open access archive for the deposit and dissemination of scientific research documents, whether they are published or not. The documents may come from teaching and research institutions in France or abroad, or from public or private research centers.
L'archive ouverte pluridisciplinaire HAL, est destinée au dépôt et à la diffusion de documents scientifiques de niveau recherche, publiés ou non, émanant des établissements d'enseignement et de recherche français ou étrangers, des laboratoires publics ou privés. 


\title{
Mass determination of molecules of biological interest by fast heavy ions induced desorption mass spectrometry
}

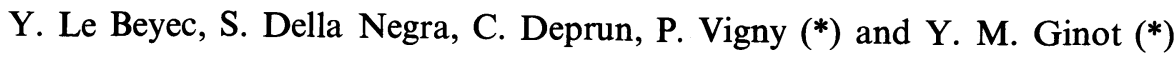 \\ Laboratoire de Chimie Nucléaire, Institut de Physique Nucléaire, B.P. no 1, 91406 Orsay, France \\ $\left(^{*}\right)$ Institut Curie et Université Paris VI $\left({ }^{* *}\right)$, 11, rue Pierre-et-Marie-Curie, 75231 Paris Cedex 05, France \\ (Reçu le 12 mai 1980, révisé le 15 septembre 1980, accepté le 17 septembre 1980)
}

\begin{abstract}
Résumé. - Il a été montré récemment que des ions lourds de grande énergie pouvaient, lors de leur passage à travers une cible mince, induire une désorption relativement douce de molécules organiques déposées sur cette cible. On a transformé un spectromètre de masse par temps de vol, construit à l'origine pour la détermination de masses de noyaux radioactifs, pour permettre la détermination de masses de grosses molécules d'intérêt biologique. Dans le présent dispositif, la désorption des molécules est obtenue par passage de fragments de fission d'une source radioactive de ${ }^{252} \mathrm{Cf}$ de faible intensité. Des essais préliminaires de détermination de masses ont été effectués sur des alcaloïdes. On présente par ailleurs des spectres de masse de nucléosides et de nucléosides modifiés chimiquement, dont l'obtention facile par cette méthode pourra trouver des applications intéressantes en Biophysique.
\end{abstract}

\begin{abstract}
It has been shown recently that fast heavy ions can induce a mild desorption of organic molecules deposited on a thin foil, when passing through the foil. A time of flight mass spectrometer, originally developed to identify the mass of radioactive nuclei, has been slightly transformed to allow the determination of the mass of large molecules. The desorption of the molecules is at the present time obtained by the fission fragments of a radioactive source ${ }^{252} \mathrm{Cf}$. Preliminary results on mass determinations and mass spectra are reported in the field of alkaloids and of nucleosides.
\end{abstract}

1. Introduction. - A time of flight mass spectrometer has been developed in Orsay to identify the mass of radioactive atomic nuclei [1]. According to the basic idea of R. D. Macfarlane and D. F. Torgerson [2], the spectrometer has been modified in order to measure masses of molecules with high molecular weight. With only minor technical changes, the system can now be used either on line with the heavy ions accelerator ALICE for studying new isotopes and nuclear reactions [3], or without, for a new approach in molecular mass spectrometry.

2. Experimental method. - A schematic diagram of the mass spectrometer is shown in figure 1. Fission fragments from a ${ }^{252} \mathrm{Cf}$ source (radioactivity by spontaneous fission) are used to bombard very small amount $\left(\sim \mu \mathrm{g} / \mathrm{cm}^{2}\right)$ of the substance deposited onto a thin $\mathrm{Ni}$ foil. It is known that fission fragments are distributed over the mass range 80-130 a.m.u. and their kinetic energies are typically around $1 \mathrm{MeV} /$

(**) Laboratoire associé au C.N.R.S. nº 198

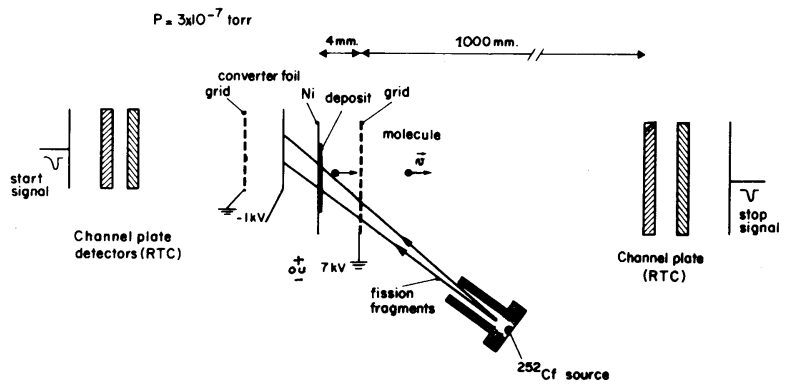

Fig. 1. - Schematic diagram of the time of flight mass spectrometer.

a.m.u. Their passage through the foil and the deposited material creates ionisation and desorption of molecules which are accelerated, within a few millimeters, by a homogeneous electric field before entering a drift tube of 1 meter length. Behind the $\mathrm{Ni}$ foil backing, the fission fragment passes through another foil $\left(100 \mu \mathrm{g} / \mathrm{cm}^{2}\right)$ where it generates electrons. These electrons are used to initiate a start signal in the channel plates detector (C.E.M.A.). When a molecule has been desorbed, it arrives at the extremity of the drift tube and triggers a set of double channel plate detectors 
which delivers a stop signal. Alpha particles are also emitted from the ${ }^{252} \mathrm{Cf}$ source ( $97 \% \alpha, 3 \%$ fission) but they generate, in the $100 \mu \mathrm{g} / \mathrm{cm}^{2} \mathrm{Ni}$ foil, much fewer electrons than the fission fragments. Therefore, the output signal is smaller than the fission fragments signal and can be easily eliminated with a lower threshold on the timing discriminator. Typical values of time of flight are in the microsecond range whereas the measured time resolution is around $0.5 \mathrm{~ns}$. When operating, the pressure inside the flight tube is $\sim 3 \times 10^{-7}$ torr. The electronic device is composed of standard nuclear electronics. It includes 2 timing discriminators, time amplitude converter, analogic digital converter and multichannel analyser (4000 or 8000 channels). The analyser is connected to an IBM computer so that the recorded spectra can be stored on disk for subsequent analysis. In the very near future, the time amplitude converter will be replaced by a one start-multistop module. For one start signal this system will accept 31 stop signals for a preset total time of flight of 16 up to $128 \mu \mathrm{s}$. The time resolution is less than $1 \mathrm{~ns}$ and the dead time less than $50 \mathrm{~ns}$. A description of this electronic device with its characteristics will be published soon [4]. The major interest of this system is that it will allow to record time-correlated events and therefore to have information on the fragmentation patterns and on the desorption mechanism as well. In addition, the efficiency of detection (assuming a constant efficiency of the C.E.M.A.) will also be independant of the values of the molecular masses.

3. Experimental results. - In order to make first tests of the method with our experimental set up we have measured the mass spectra of the two alkaloids Atropine $\left(\mathrm{C}_{17} \mathrm{NO}_{3} \mathrm{H}_{23}, M=289.4\right)$ and Reserpine $\left(\mathrm{C}_{33} \mathrm{~N}_{2} \mathrm{O}_{9} \mathrm{H}_{40}, M=608.7\right)$, for which similar measurements have been already performed by Becker $e t$ al. in Germany [5]. Figure $2 a$ shows the positive spectrum of Atropine with the two main peaks at $M=290$, which corresponds to the formation of $(M+\mathrm{H})^{+}$, and at $M=124$ which is due to the rupture of a bond as shown in the figure. Figure $2 b$ shows the expanded part of the mass region around 290 which indicates the good mass resolution which can be achieved $(M / \Delta M \sim 800)$. As it has been noted before, positive and negative spectra can be obtained. For example Reserpine (Fig. 3) exhibits peaks at $M=609$ and $M=607$ which correspond to the quasi molecular ions $(M+\mathrm{H})^{+}$and $(M-\mathrm{H})^{-}$respectively. In this case, there is also some fragmentation leading to peaks at 365, 398 and around 195. These spectra have been recorded during about $30 \mathrm{~min}$. with a ${ }^{252} \mathrm{Cf}$ source giving 100 start fission events per second. No background has been substracted. In the first part of the spectra which is not shown here, numerous and intense peaks of $\mathrm{H}^{+}, \mathrm{H}_{2}^{+}, \mathrm{H}_{3}^{+}, \mathrm{Na}^{+}, \mathrm{K}^{+}$and $\mathrm{C} x \mathrm{H} y^{+}$ are always present. They are useful for mass-channel calibration according to the simple expression : channel (time) $=a \sqrt{M}+b$.

Although the mechanism of desorption is not well understood, the method has been applied to measure the mass of biologically important molecules namely nucleosides. Figures 4-7 show the positive spectra for Adenosine $\left(\mathrm{C}_{10} \mathrm{~N}_{5} \mathrm{O}_{4} \mathrm{H}_{13}\right)$, Guanosine $\left(\mathrm{C}_{10} \mathrm{~N}_{5} \mathrm{O}_{5} \mathrm{H}_{13}\right)$, Cytidine $\left(\mathrm{C}_{9} \mathrm{~N}_{3} \mathrm{O}_{5} \mathrm{H}_{13}\right)$ and Thymidine $\left(\mathrm{C}_{10} \mathrm{~N}_{2} \mathrm{O}_{5} \mathrm{H}_{14}\right)$. The formation of molecular ions with ion dipole attachment $(M+\mathrm{H})^{+},(M+\mathrm{Na})^{+}$and $(\mathrm{B}$ (base

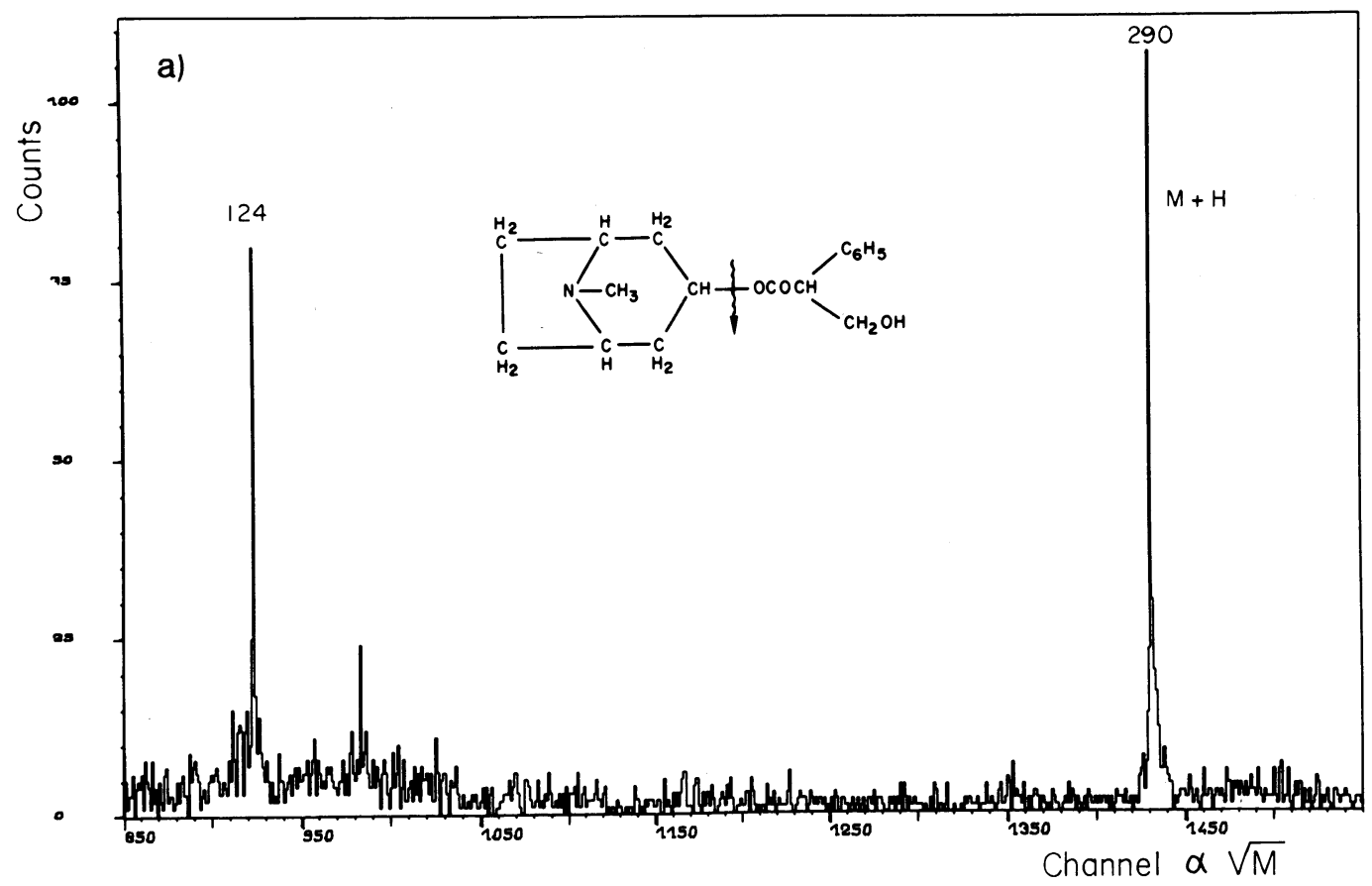

Fig. $2 a$. - Mass spectrum of the alkaloid Atropine dominated by the molecular ion $(M+\mathrm{H})^{+}$at $M=290$ and showing a peak at $M=124$ corresponding to the left part of the molecule after rupture of the ester bond as shown by the arrow. 


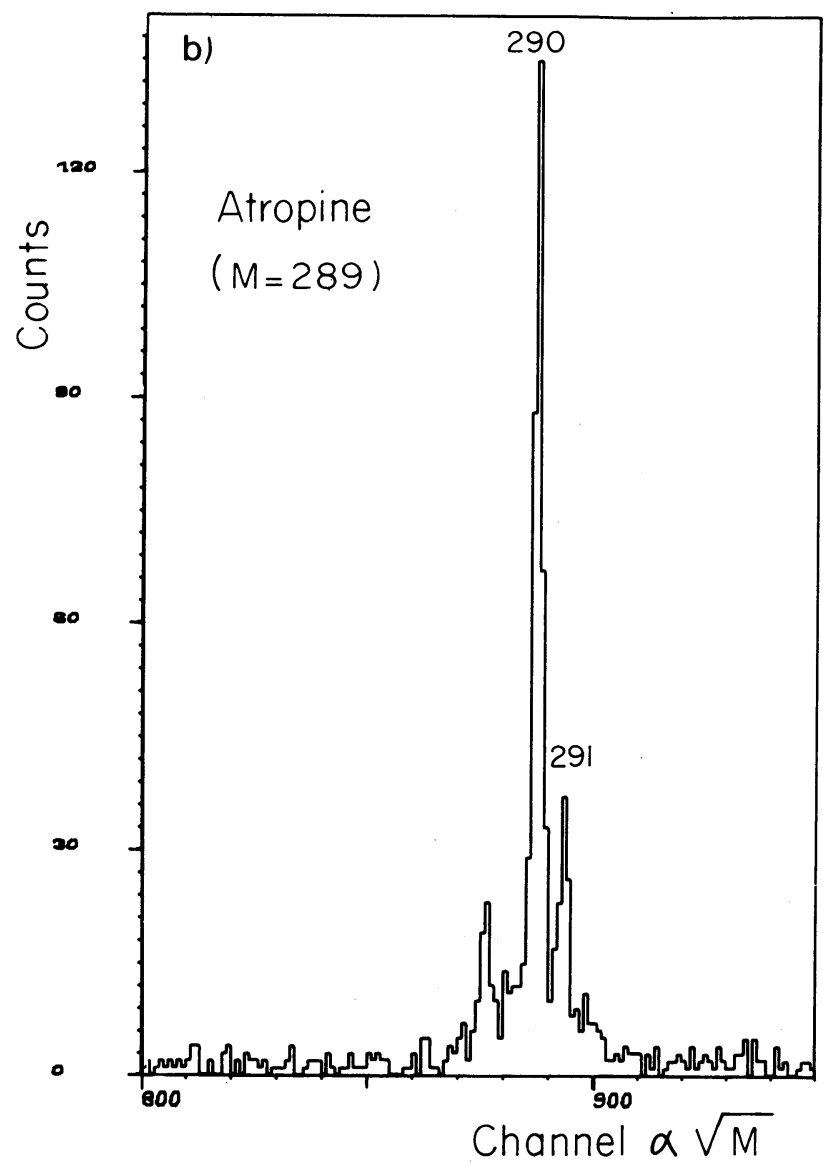

Fig. 2b. - Expanded part of the Mass spectrum of Atropine around the molecular ion $(M+H)^{+}$. residue) $+2 \mathrm{H})^{+}$are characteristic for these spectra. It is obvious that in some cases the desorption of $(M+\mathrm{Na})^{+}$occurs simultaneously with the desorption of lighter species like either $\mathrm{Na}^{+}, \mathrm{K}^{+}, \mathrm{C} x \mathrm{H} y^{+}$or molecular fragments corresponding for example to the rupture of the glycosidic bonds. Therefore, due to the electronic system (T.A.C.), only the first ion which arrives at the extremity of the tube is recorded. A simple test to demonstrate the highest detection probability of light ions is to delay the start signal in order to eliminate in the spectrum the peak corresponding to the base (and other lighter species) and to compare, for a given number of start events, the $(M+\mathrm{Na})^{+}$events recorded in spectra with and without delay. The delay procedure enhances the molecular $(M+\mathrm{Na})^{+}$peak intensity by almost a factor 3 . The relative intensity of the peaks in figures 4-7, between the base and the molecular ions are thus not correct but we wanted to show the most interesting part of the whole spectra.

As a first attempt to check if the present technique can be useful for an easy detection of any chemical modification of nucleosides, measurements have also been made for methylated nucleosides. Figure 8 ( $a$ and b) shows such a spectrum for 7-Methylguanosine, a residue which is often produced during the attack of DNA by some alkylating carcinogenic agents. Peaks at 166 (methylated guanine residue) and at 298 $(M+\mathrm{H})^{+}$allow an unambiguous identification of the modified nucleoside. The spectra correspond to measurement after $60 \mathrm{~min}$. In figure $8 b$ the delay of

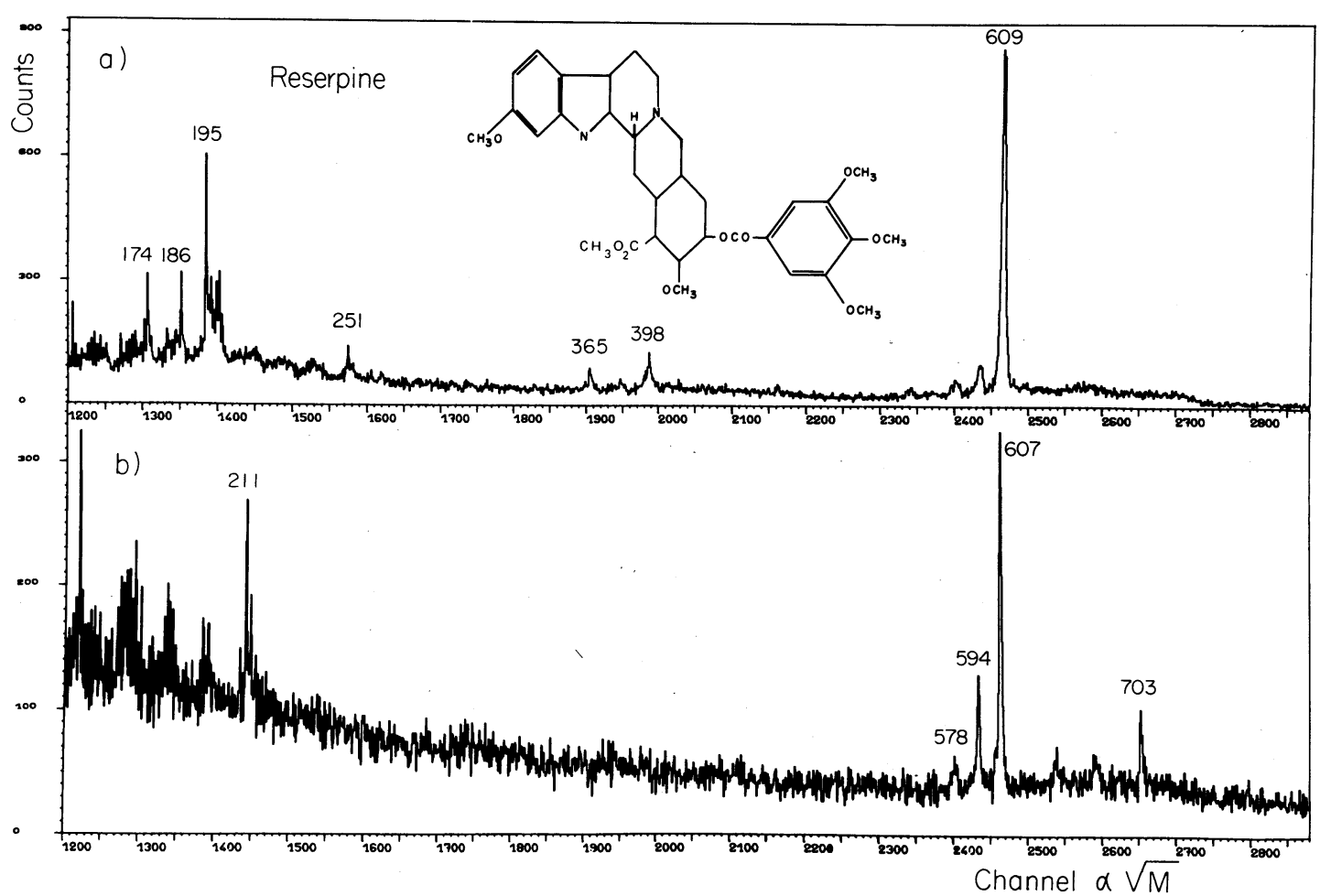

Fig. 3. - Mass spectra of the alkaloid Reserpine : a) positive ions dominated by the molecular ion $(M+\mathrm{H})^{+}$at $\left.M=609 ; b\right)$ negative ions dominated by the molecular ion $(M-\mathrm{H})^{-}$at $M=607$. 


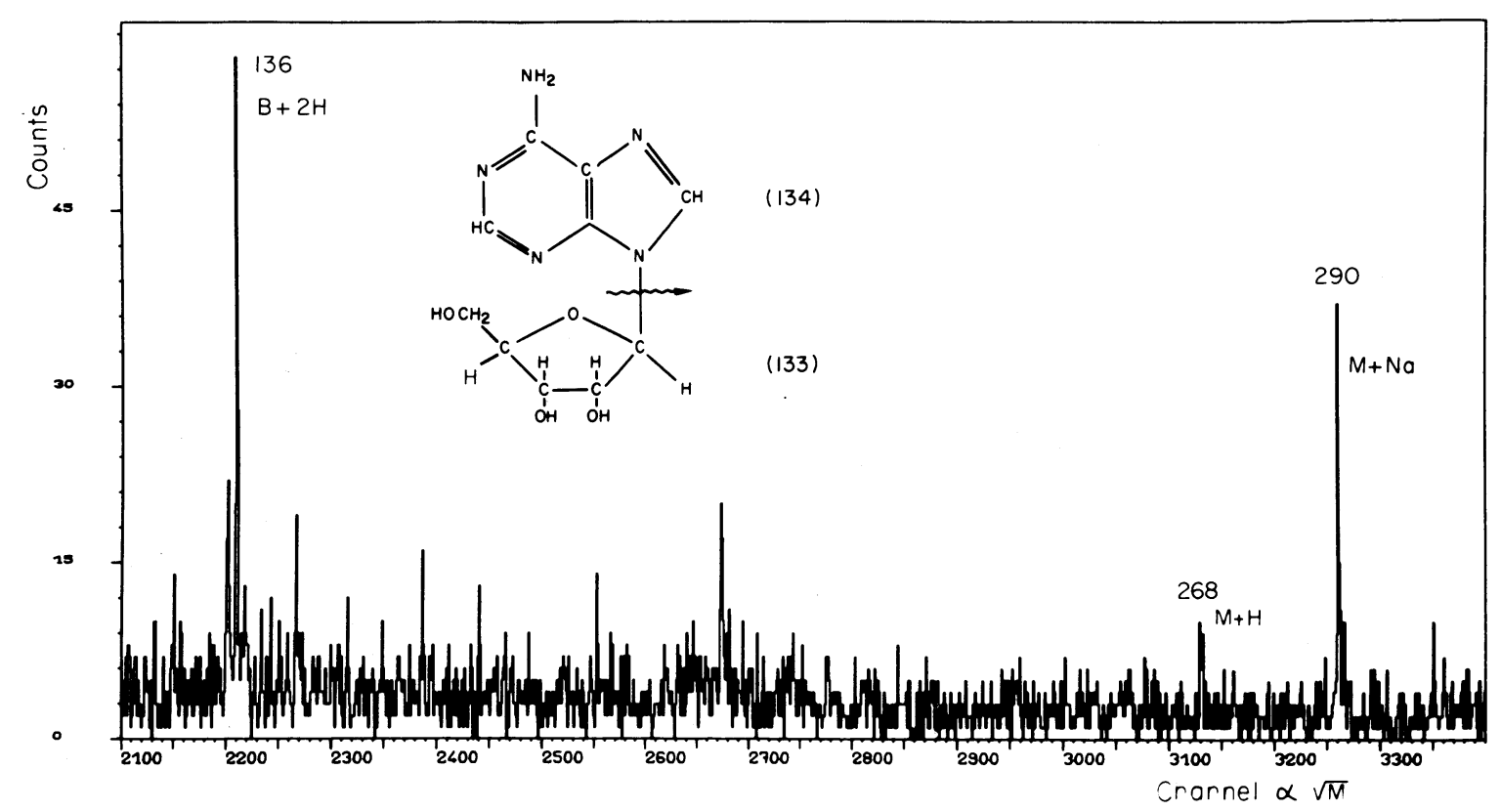

Fig. 4. - Mass spectrum of the nucleoside Adenosine showing the molecular ion $(M+\mathrm{H})^{+}$at $M=268$, the ion dipole attachment $(M+\mathrm{Na})^{+}$at $M=290$ and the base residue $(\mathrm{B}+2 \mathrm{H})^{+}$at $M=136$ after rupture of the $\mathrm{N}$-glycosidic bond as shown by the arrow.

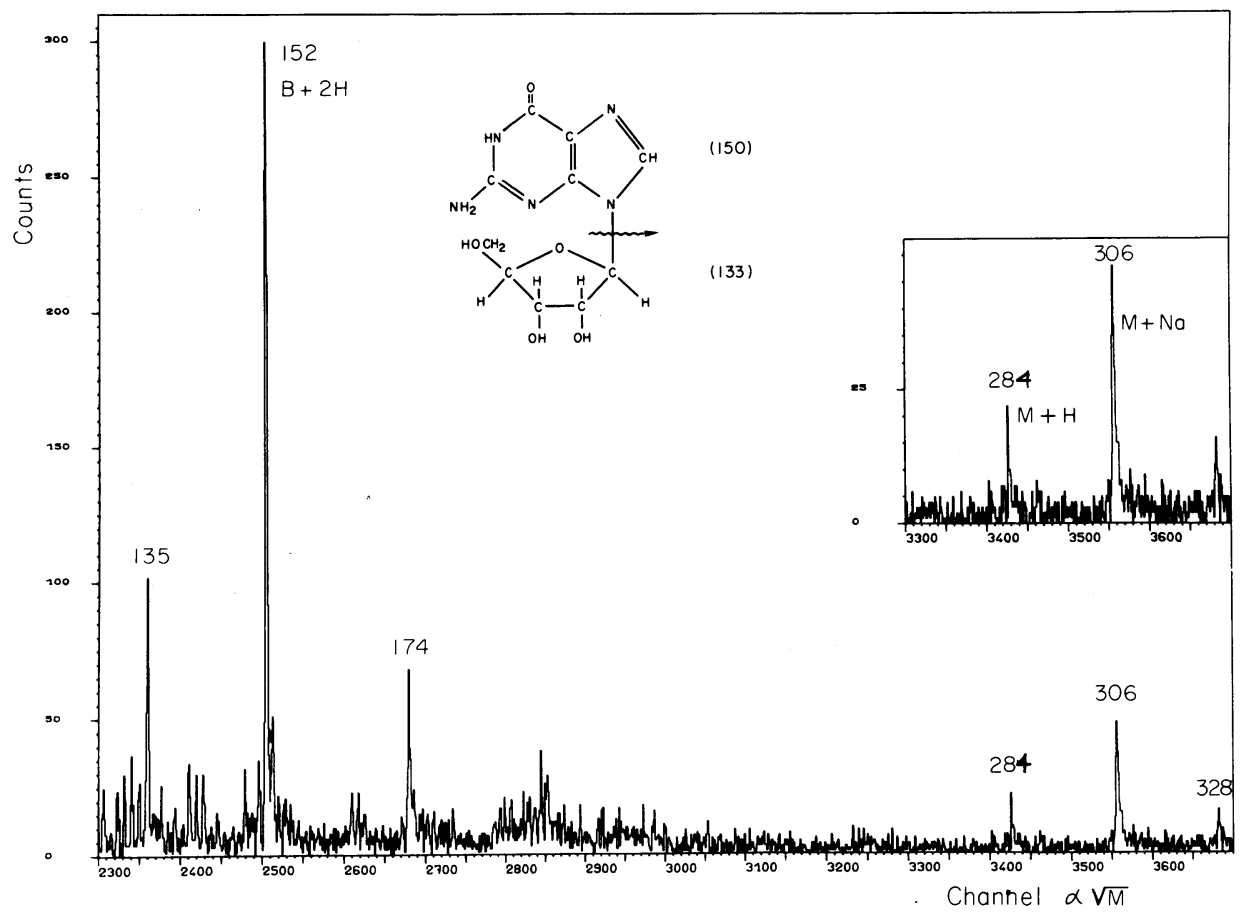

Fig. 5. - Mass spectrum of the nucleoside Guanosine showing the molecular ion $(M+\mathrm{H})^{+}$at $M=284$, the ion dipole attachment $(M+\mathrm{Na})^{+}$at $M=306$ and the base residue $(\mathrm{B}+2 \mathrm{H})^{+}$at $M=152$ after rupture of the $\mathrm{N}$-glycosidic bond as shown by the arrow.

the start signal was adjusted in order to eliminate the base. Under these conditions the molecular peak intensity is increased by a factor 2.5 .

4. Discussion. - Investigation of the fission fragment induced desorption mechanism requires specific experimental results such as axial and radial energy distributions and angular distributions of the desorbed molecular ions. Contributions to the understanding of the processes were made by the group from Darmstadt $[6,7,8]$ which also described a mass spectrometer using this desorption procedure [9]. A different and interesting approach was also made by $\mathrm{P}$. Dück $e t$ al. [10] by using ion beams of ${ }^{16} \mathrm{O}$ and ${ }^{32} \mathrm{~S}$ instead of fission fragments. The results are interpreted in terms of a Coulomb field perturbation created by the electron 


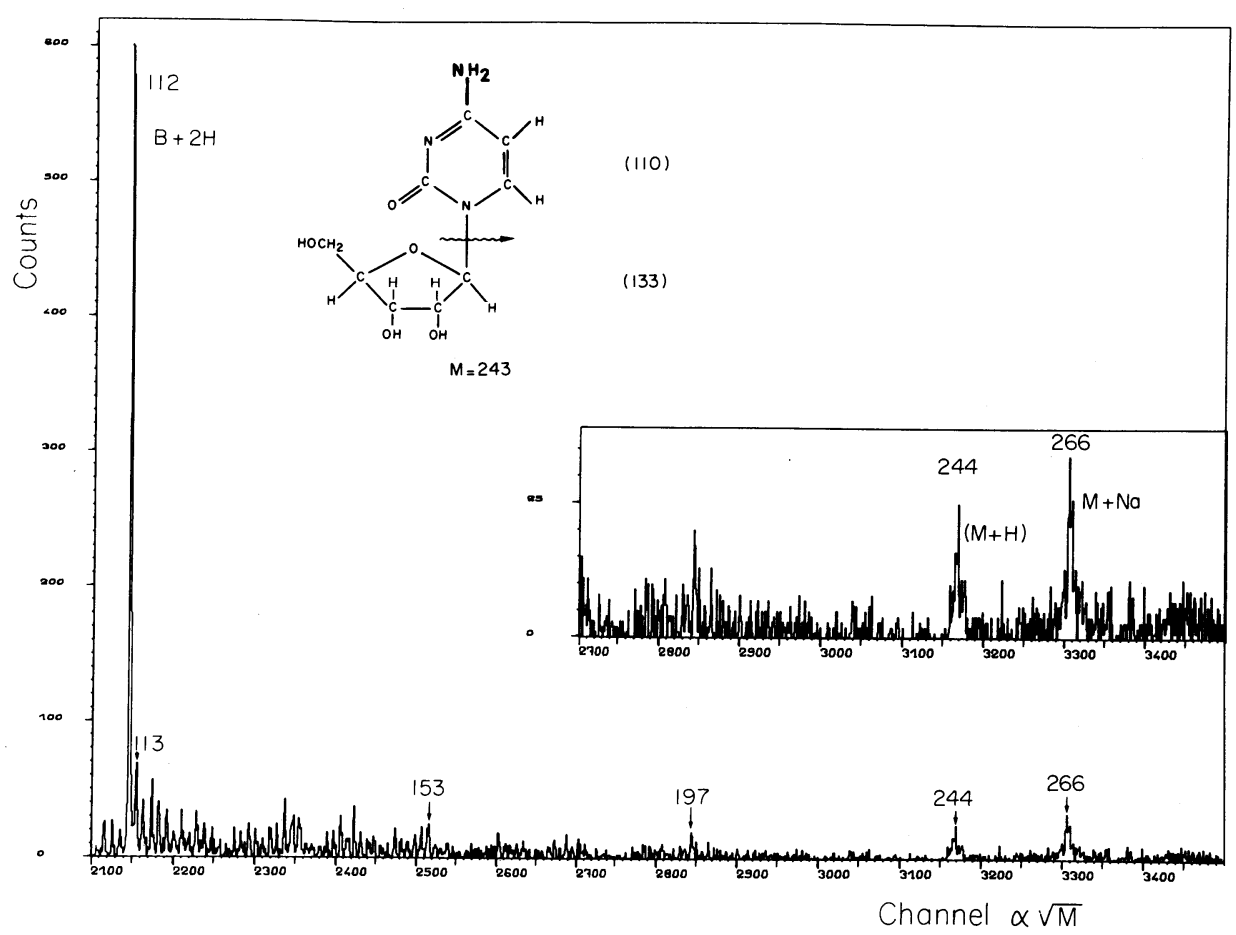

Fig. 6. - Mass spectrum of the nucleoside Cytidine showing the molecular ion $(M+H)^{+}$at $M=244$, the ion dipole attachment $(M+\mathrm{Na})^{+}$at $M=266$ and the base residue $(\mathrm{B}+2 \mathrm{H})^{+}$at $M=112$ after rupture of the N-glycosidic bond as shown by the arrow.

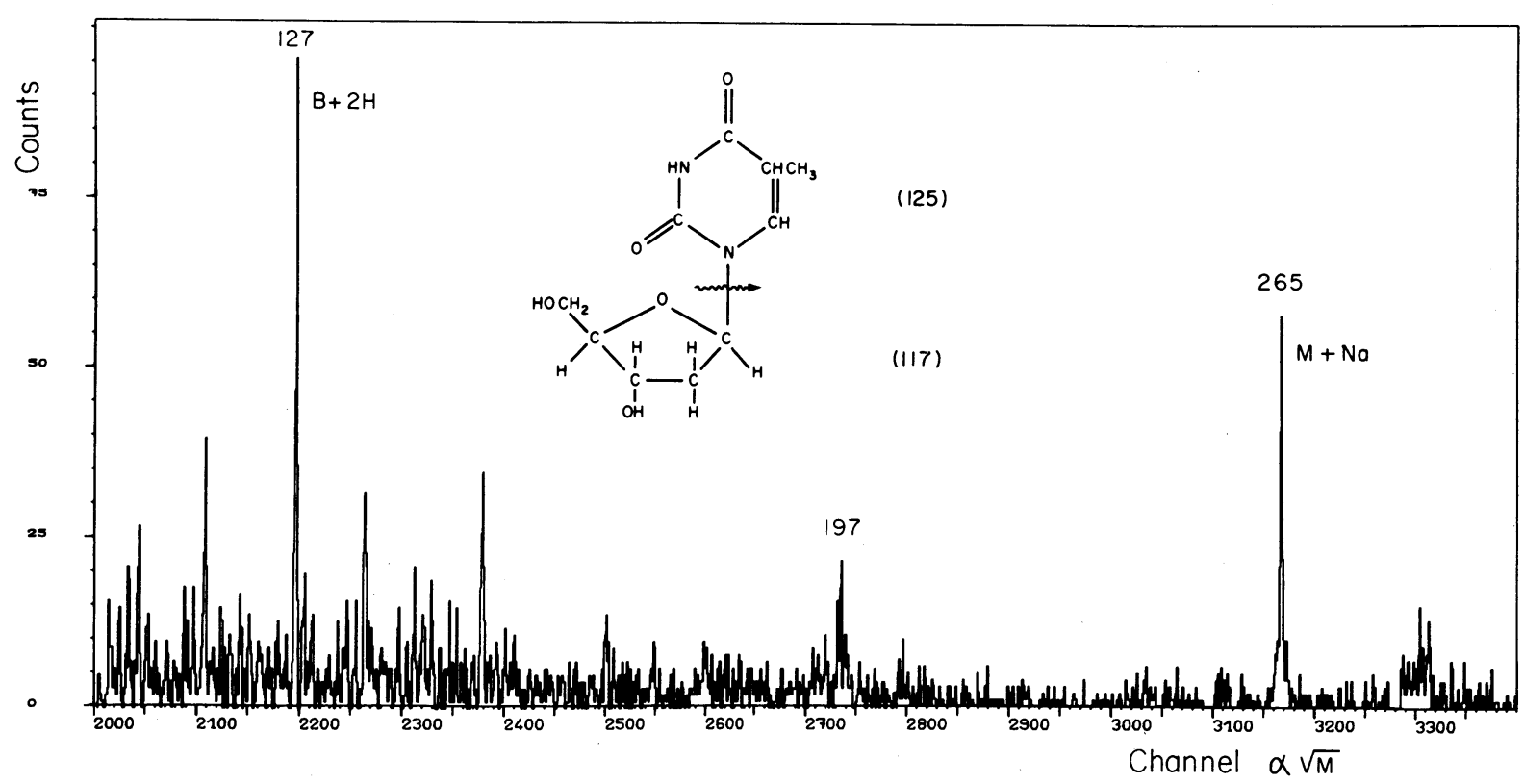

Fig. 7. - Mass spectrum of the nucleoside thymidine showing the ion dipole attachment $(M+\mathrm{Na})^{+}$at $M=265$ and the base residue $(\mathrm{B}+2 \mathrm{H})^{+}$at $M=127$ after rupture of the N-glycosidic bond as shown by the arrow.

plasma excitation which, at a distance from the passage of the fission fragment through the sample, affects the binding states of the molecules at the surface. The energy transferred to the molecules is small. It can be roughly evaluated from the width of the peaks in the time of flight spectra and for example the figure 2 led to the conclusion that the initial energy is smaller than $15 \mathrm{eV}$. Application of the present method have been essentially developed by R. D. Macfarlane and collaborators for the determination of large masses of non-volatile biological molecules [11-14]. Molecular ion peaks above 12000 have already been observed by this group [15].

Our field of application is, for the moment, limited to mass measurements and the identification of modified nucleosides and of some larger involatile organic 


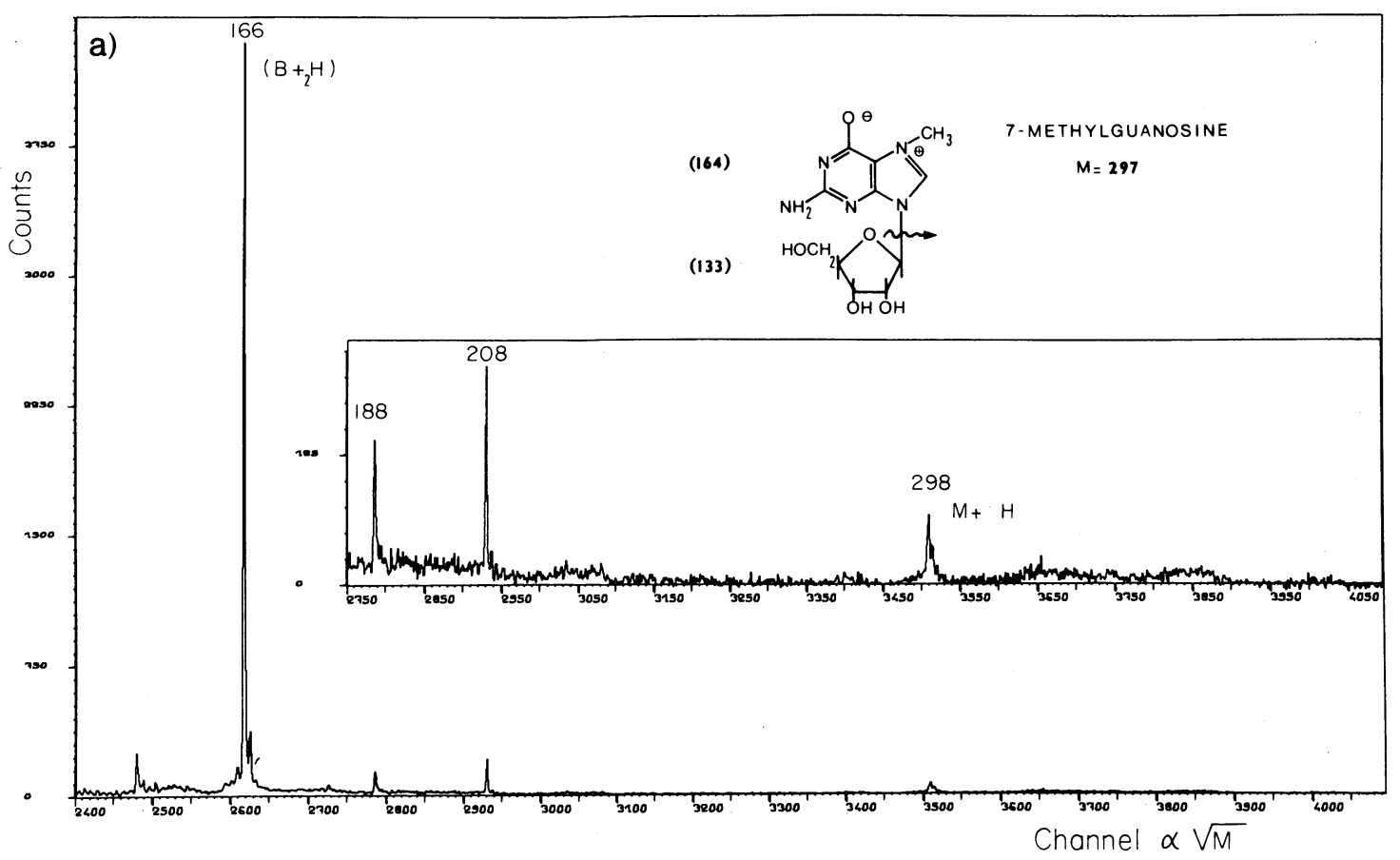

Fig. 8a. - Mass spectrum of the modified nucleoside 7-Methyl guanosine showing the molecular ion $(M+\mathrm{H})^{+}$at $M=298$ and the base residue $(\mathrm{B}+2 \mathrm{H})^{+}$at $M=166$ after rupture of the $\mathrm{N}$-glycosidic bond as shown by the arrow.

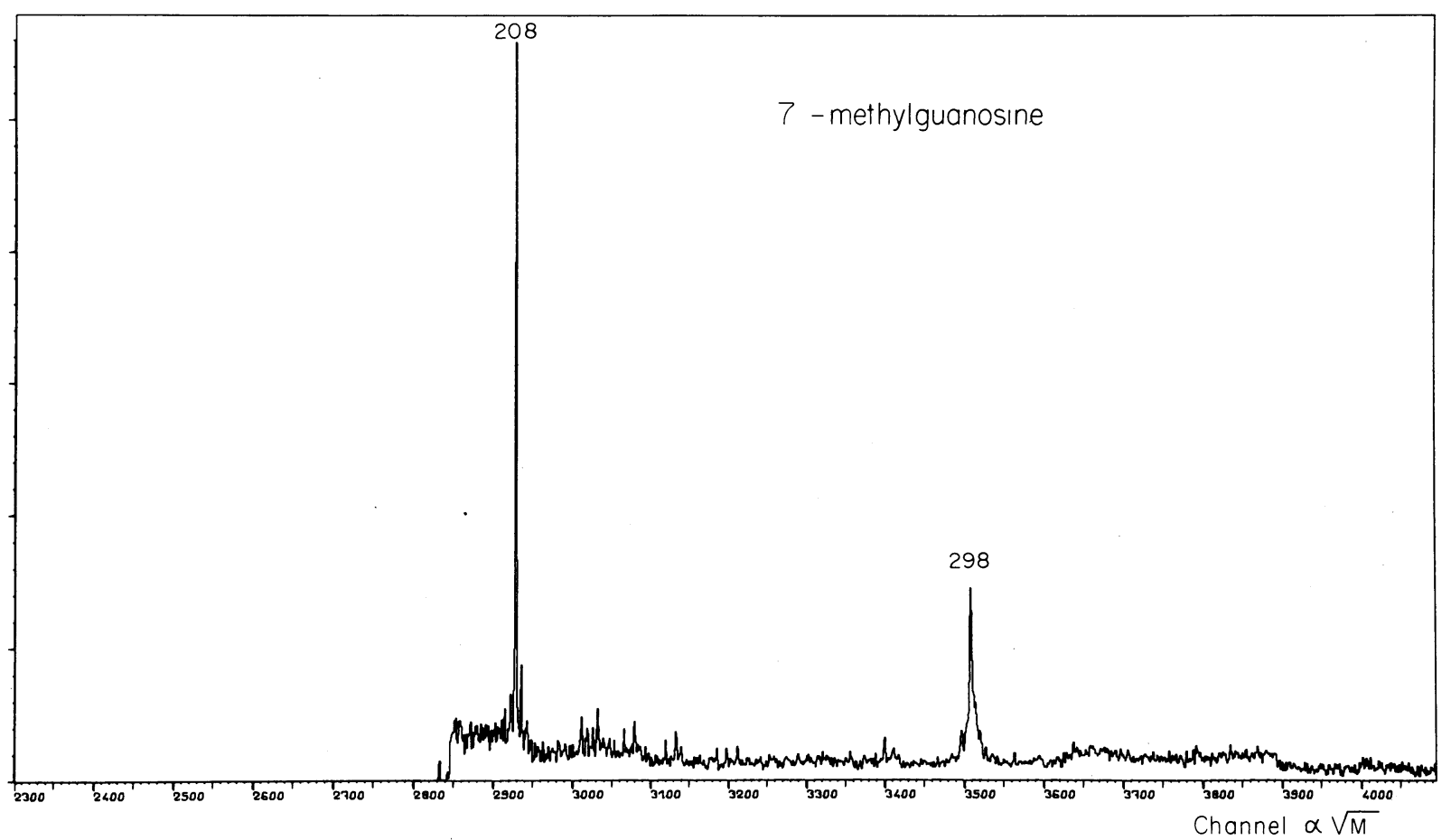

Fig. $8 b$. - Mass spectrum of 7-Methylguanosine recorded with a delay on the start signal which eliminates the base peak and increases the molecular $(M+\mathrm{H})^{+}$peak intensity by a factor 2.5 .

molecules. Other mass spectrometry techniques such as electron impact $[16,17]$, chemical ionisation $[18,19]$ or field desorption $[20,21,22]$ have been applied to free nucleosides. Our results are comparable to those obtained by these techniques. Fragmentation patterns are very similar to those obtained by chemical ionisa- tion [18] though the production of quasi molecular ions by proton transfer or $\mathrm{Na}$ attachment is perhaps less than that observed by field desorption [22]. The sensitivity of the method lies at the moment, in the range of microgramme but could be improved in the near future. Our results are comparable to those 
obtained by the field desorption techniques. One must note that mass spectra of the 7-methylguanosine are particularly difficult to obtain by any other methods. There are still some technical problems to be solved in order to increase the versatility of our plasma desorption mass spectrometry system (P.D.M.S.). We have found that surface effects are extremely important as well as the way of preparing the deposit. In many cases, we have been able to verify that the method is undestructive. Quantitative measurements on the weight of products were performed before and after the mass analysis. For nucleosides, the $\mathrm{Ni}$ foils were washed with methanol and the concentration of the product was determined by absorption measurements. Around $70 \%$ of the total amount was recovered. This is of considerable interest with regard to the cost of some products or when the products are biochemically difficult to prepare. Such is the case of a series of nucleosides modified by chemical carcinogens which we are presently studying by this technique and for which the technique seems to be promising.

In addition to these very specific studies on biological molecules, the development of the technique is being pursued. The simplicity of the method itself as well as the advantages reported above allow to predict a rapid extention of the technique in the near future in the field of mass spectrometry. Moreover it is thought that information about fundamental chemical problems could also be obtained by studying fragmentation and lifetime of specific bonds in molecules, but this constitutes another field of applications.

Acknowledgments. - The authors wish to acknowedge Prof. M. Duquesne for his encouragements in this work and Alié Brunissen for her technical assistance.

\section{References}

[1] Della Negra, S., Deprun, C., Jungclas, H., Gauvin, H. and Le BeYEC, Y., Nucl. Instrum. Methods 150 (1978) 355.

[2] Torgerson, D. F., Skowronski, R. P. and Macfarlane, R. D., Biochem. Biophys. Res. Commun. 60 (1974) 616-621.

Macfarlane, R. D. and Torgerson, D. F., Science 191 (1976) 920-925.

[3] Della Negra, S., Deprun, C., Gauvin, H., Husson, J. P. and LE BeYEC, Y., IPNO-RC-79.04 (1979) and to be published.

[4] Festa, E., Sellem, R., to be published.

[5] BeCKer, O., Fürstenau, N., KNIPPelberg, W. and KrUeger, F. R., Org. Mass Spectrom. vol. 12 (1977) 7.

[6] Fürstenau, N., Knippelberg, W., Krueger, F., Weis, G. and WIEN, K., Z. Naturförsch. 32a (1977) 711.

[7] Krueger, F. R., Surf. Sci. 86 (1979) 246-256.

[8] KRUEGER, F. R. and Wien, K., Z. Naturförsch. 33a (1978) 638-643.

[9] Becker, O., Fürsternau, N., Krueger, F. R., Weiss, G. and WIEN, K., Nucl. Instrum. Methods 139 (1976) 195.

[10] Dück, P., Treu, W., Galster, W., FröHLICh, H. and VoIt, H., Nucl. Instrum. Methods 168 (1980) 601.

[11] McNeal, C. J., Narang, S. A., Macfarlane, R. D., Hsiung, H. M. and Brousseau, R., Proc. Natl. Acad. Sci. U.S.A. 77 (1980) 735.
[12] Macfarlane, R. D., McNeal, C. J. and Hunt, J. E., Proc. Int. Mass Spectrom. Conf. Oslo (1979).

[13] Hunt, J. E., Macfarlane, R. D., Katz, J. J. and Douglent, R. C., Proc. Natl. Acad. Sci. U.S.A. (1980).

[14] PIPER, D. G., Doctoral thesis, Texas A and M University (1976).

[15] McNeal, C. J., Doctoral thesis, Texas A and M University (1980).

[16] McCloskey, J. A., in Basic Principles in Nucleic Acid chemistry. P.O.P. Ts'O Ed. (Acad. Press N.Y.) 1974.

[17] HIGNITE, C., in Biochemical applications of mass spectrometry, Edited by G. R. Waller and O. Dermik (J. Wiley Interscience) 1972.

[18] Wilson, M. H. and McCloskey, J. A., 21th Annual conference on Mass Spectrometry and allied topics San Francisco (1973) p. 276

[19] Burlingame, A. L., Shackleton, C. H. L., Howe, I. and Chizkov, O. S., Anal. Chem. 50 (1978) 346-384.

[20] Schulten, H. R. and BeCKey, H. D., J. Org. mass spectrometry 6 (1972) 885.

[21] Fenselan, C., Kan, M. N. N. and Sack, G. H., Wood, G. W., SCHMIDT, D. E. and LAN, P. Y., Adv. Mass spectrom. 713 (1976).

[22] Schulten, H. R., Int. J. Mass Spectrom. Ion Phys. 32 (1979) 97-283. 